\title{
SELECTED ASPECTS OF VEHICLE BORN IMPROVIZED EXPLOSIVE DEVICES
}

\author{
Luděk RAK, Jan DROZD, Zdeněk FLASAR
}

\author{
University of Defence, Brno, The Czech Republic \\ ludek.rak@unob.cz, jan.drozd@unob.cz, zdenek.flasar@unob.cz
}

\begin{abstract}
The paper focuses on the analysis of the current highly dangerous tools of destruction, used mostly by insurgents and terrorists, especially in asymmetric warfare. Vehicles usually loaded with explosives (mostly homemade explosive), driven by suicide bombers are a significant threat to troops and the civilian population, not only in high risk areas. Analysis of the available incidents of this type, and available response to an incident mentioned in this article, it becomes the basic portfolio data for the design of effective elimination or at least reduction of the destructive effect, especially on soft targets.
\end{abstract}

\section{Keywords: IED, VBIED, Tactics, Barrier}

\section{Introduction}

Improvised explosive devices (IED) are devices used in armed conflicts for a long time. Especially the war in Afghanistan and Iraq in the early $21^{\text {st }}$ century, stress out the importance of this phenomenon among insurgent tactics. The IED in some materials referred to as the so-called "roadside bombs" - explosives planted by roads, which is not the exact meaning. Extensive use of IEDs has become typical, especially for insurgents in destinations with ethnic and religious unrest where some multinational operation was authorised. In the years 2003 - 2008 IEDs planted by insurgents caused the largest number of death and serious injury to members of the coalition forces, mainly American soldiers. In some sense, we can talk about an IED as a means of warfare, from another point of view we can talk about tactics. The use of IED is gradually developing in a similar way as other means of warfare, weapons and tactics. In terms of effects of IED there is an increasing evidence of the use of explosives being transported to a destination on vehicles. This specific group of IEDs is generally referred as VBIED
(Vehicle-Borne Improvised Explosive Device) or SVBIED (Suicide VehicleBorne Improvised Explosive Devices).

In order to effectively operate against VBIED (SBVIED), it is necessary to find answers to questions WHY, WHEN, WHERE and HOW these IEDs are used by insurgents. Based on the VBIED development and partial analysis of a use of some VBIED in contemporary armed conflicts, the authors of the article tries to find defense possibilities against this means or tactics.

\section{Partial analysis of recent selected VBIED attacks}

In selected VBIED attacks, authors tries to find answers to the above mentioned questions - WHY, WHEN, WHERE and HOW these devices were used. It is obvious, or at least very likely to assume that all of these questions can be answered in each case exactly the same or very similar manner.

To answer the question WHY terrorists used VBIED could be answered as follows:

- to destabilize the political (economic, military, ...) situation on the territory, 
- to discredit peacekeeping forces on the territory (to provoke hatred of local population towards peacekeepers),

- to cause casualties (injuries) to the part of the population which sympathizes with peacekeepers and cause damage to infrastructure,

- to demonstrate the influence and power in the territory,

- to enforce different approaches (affecting the local elections, the release of detainees, which have interested terrorists etc.).

- to answer the question WHEN terrorists used VBIED answers could be:

$\checkmark$ in tense situations on the territory, when the terrorists lose influence over the local population, or when peacekeepers achieved significant success in fighting,

$\checkmark$ unexpectedly, surprisingly, at any time of year and day (night) time; the right to choose the time of the VBIED attack is one of the biggest advantages of terrorists.

- to answer the question WHERE terrorists used VBIED answers could be:

$\checkmark$ in places with large concentration of civilians - the local population (socalled. "Soft targets") to achieve the maximum effect (killed and injured as many people as possible),

$\checkmark$ in place and buildings controlled by official authorities and security forces of the country (embassies of other countries, government offices, police stations and military installations),

$\checkmark$ in objects controlled by peacekeeping forces (permanent and temporary / forward / bases, checkpoints, etc.).

- to answer the question HOW terrorists use VBIED could be answered as follows:

$\checkmark$ by driving explosives loaded in vehicle to the vicinity of the planned attack targets (typically with a suicide driver; exceptionally without him who has left the vehicle before the explosion), and detonating the explosive,

$\checkmark$ in combination with other forms of attack (with walking shooters who open fire before using VBIED, or even after explosion)

$\checkmark$ using a secondary VBIED when after the explosion of the first VBIED and caused confusion the secondary VBIED is exploded.

\subsection{The attack in IZMIR, Turkey}

In early January 2017 there was a car explosion loaded with explosives outside the courthouse in the west of Turkey. Sources reported that the explosion occurred killing at least two people and injured five other people.

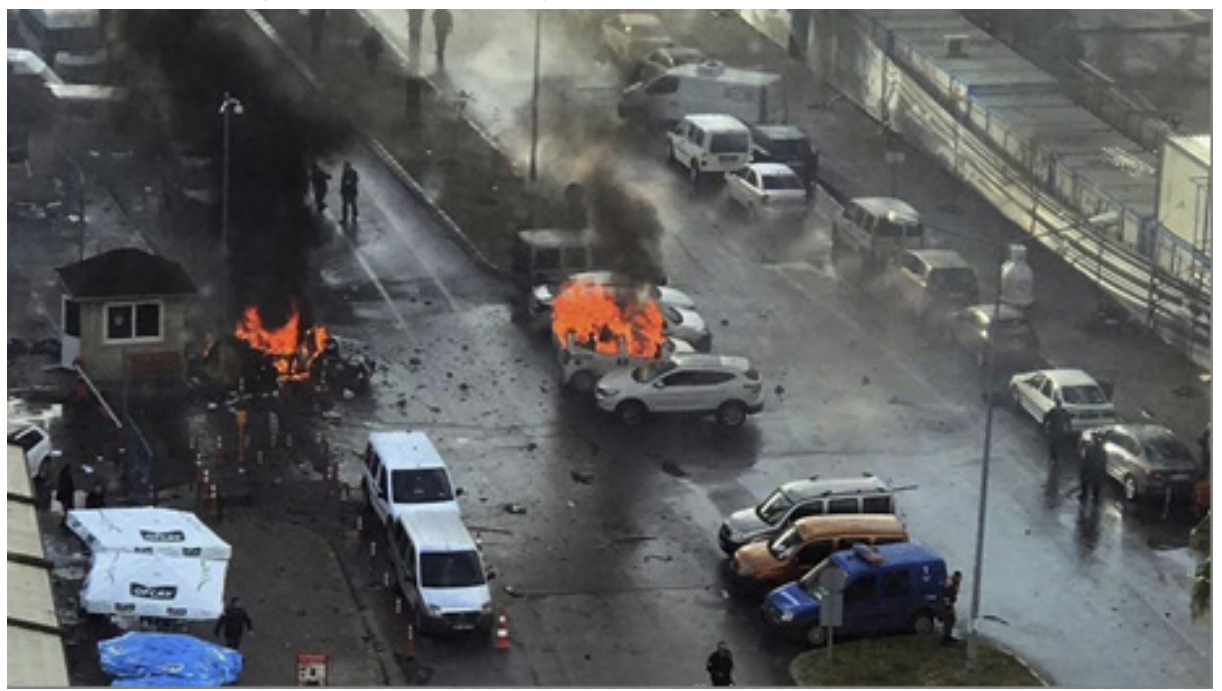

Figure 1: The consequences of an attack with explosives in Izmir Source: $\check{C} T K / A P$

Basic facts about the attack, which was officially released on the basis of the investigation of the incident:
- explosion of a vehicle was accompanied by a dismounted terrorist elements armed with small arms and grenades. 
- the quantity of explosives (or its estimate) mounted on the car were not disclosed,

- sources differ whether the shooting was preceded by an explosion, or vice versa,

- the attack took place in front of the government installation - at the entrance to the courthouse in the district Bayrakli Izmir, which is designed for judges and prosecutors,

- by the governor of Izmir province attack was apparently prepared and executed by members of the Partiya Karkerên Kurdistan (PKK)

- police tried to stop a suspicious vehicle at a checkpoint near the courthouse before it exploded; during this conflict terrorists detonated a bomb in the car,

- attackers most probably owned a second car which was detonated in a controlled detonation; from sources is not clear whether this controlled detonation occurred during the intervention of the courthouse or later.

\subsection{The terrorist attack in Israel}

At $8^{\text {th }}$ of January 2017 VBIED attack in Jerusalem, Israel. The attacker drove a truck into a group of soldiers; four of them did not survive the attack.

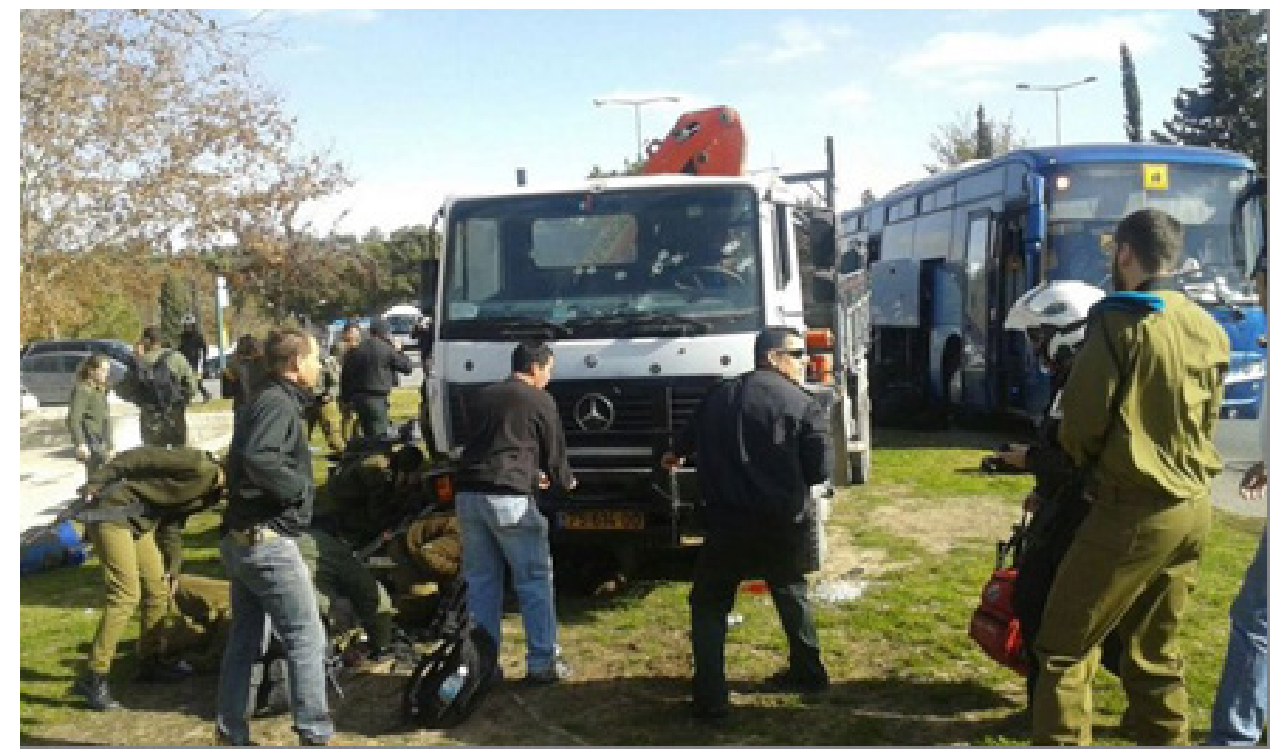

Figure 2: VBIED attack by truck loaded with explosives in Israel Source: ¿̌TK

Basic facts about the attack, which was officially released on the basis of the investigation of the incident:

- driver-attacker was a Palestinian; driver was (after the attack) shot,

- it was clearly a targeted attack on a group of Israelis serving in the armed forces - members of government

- except four fatalities (three women and one man, all aged around 20 years) other fifteen people were injured (sources did not indicate whether all of those were soldiers),

- the driver chose for attack busy promenade; drove at full speed into a crowd of soldiers who just got out of the bus, according to eyewitnesses, then backed in an apparent attempt to run over as many people as possible,

- according to sources incident can be associated with more than a year-long series of violent attacks on Israelis by Palestinians, which the perpetrators commit using knives; several times a vehicle has been also used as a weapon,

- since October 2016 during similar incidents over 230 Palestinians and 40 Israelis were killed.

\section{Problem solution way out}

VBIED represent currently the world's most effective weapon in the hands of terrorists or insurgents, which even modern armies, have not adequate response. Historically, 
this is not a modern combat means. Using cars stuffed with straw or combustibles can be traced in the middle ages, remotely operated vehicles carrying explosive charge appeared in significant numbers in World War II. In some way, in the history of warfare could be found incendiary ships, aircraft loaded with explosives that have become a significant weapon in the hands of one of the warring parties.

Since the beginning of the millennium VBIED appeared almost worldwide, gradually modify and evolve, both in relation to the proposed order, local conditions and technologies used. Their effectiveness is definitely undisputable since they are on the list of the most common types of incidents on fifth place overall.

\subsection{VBIED development}

The significance level of risk and really long existence of the weapon indicates the following facts. October 23, 1981 had two VBIED explosion in Beirut (Lebanon), resulting in 299 deaths. The reason for this high number of victims was also the fact that the bomb used was probably designed as a thermobaric. In 2007 VBIED explosion in Iraq - Kathaniye killed more than 500 dead and 1,500 wounded. These figures illustrate the fact that, especially for socalled soft targets (instead of concentrating large numbers of people, markets, hospitals, railway stations, etc.) VBIED are extreme danger. The explosion of a truck became a decisive moment in 2014 when The Islamic State took Mosul in Iraq. Nothing changed on the fact that the tanker detonated prematurely. In this case, the detonation was so powerful that destroyed two blocks of buildings. Psychological effect on soldiers fighting the Iraqi army was the same as the actual explosion - devastating. In May 2015 in the area of Al-Ramadi in Iraq a series of VBIED blast reportedly sparked effect of "nuclear weapons".

Statistically, it could be stated that most frequent used and documented VBIED attacks occurred in Iraq, Syria, Yemen and Afghanistan. However, the following chart shows that VBIED are global. The chart included survey data for the period 2012 2016 and takes into account the total number of VBIED incidents.

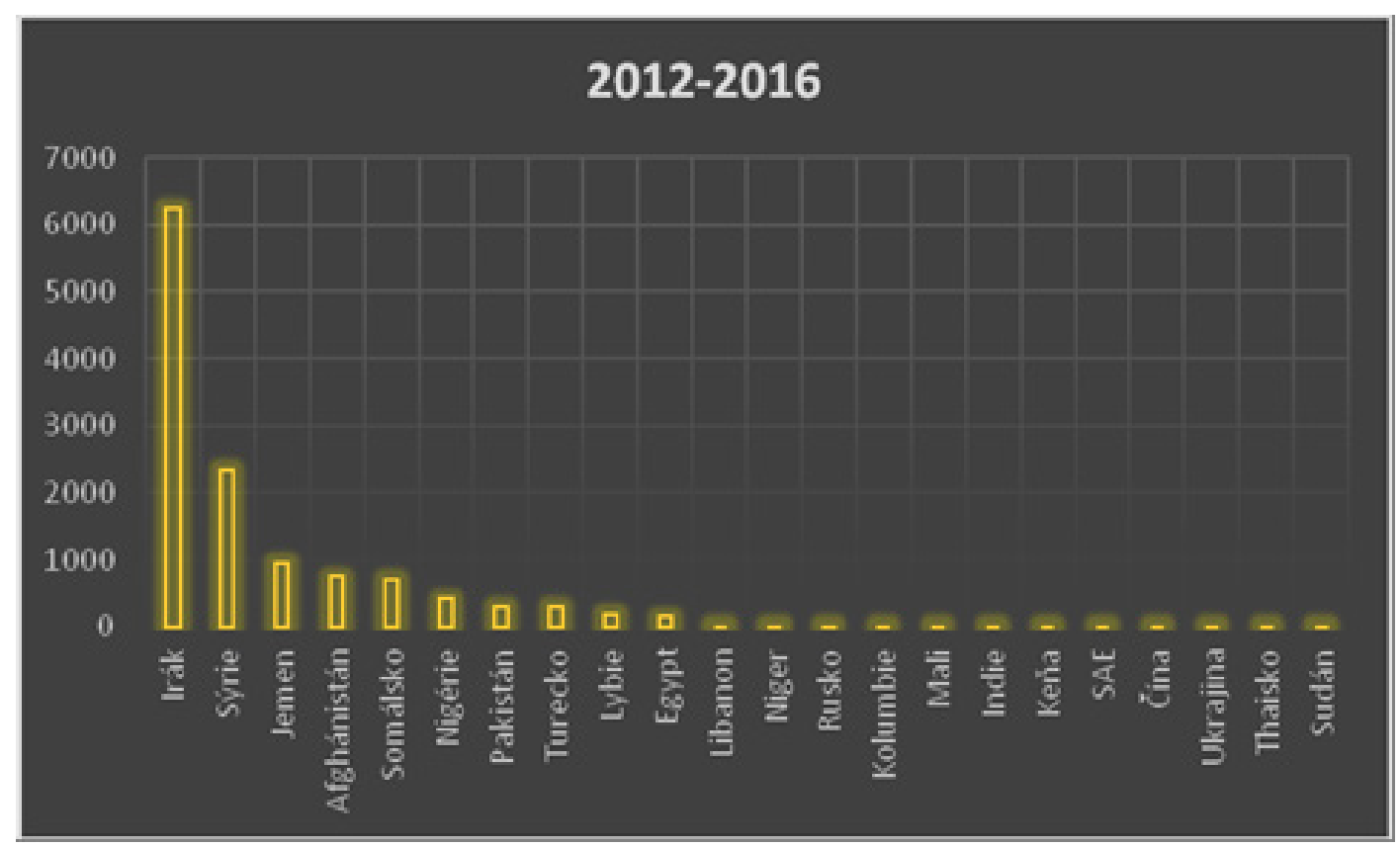

Figure 3: The number of incidents in chosen countries in the years 2012 - 2016 Source: own using https://intelcenter.com/\#gs.goqK4bk

As a vehicle transporting explosives to target are the most widely used up to 2005 small cars. It is mostly commercial vehicles with a loading area up to 3.5 tonnes. 
Sparsely appear vehicles weighing more than 5 tons. As can be found absolutely unique crawler vehicle (BMP-1, 2), or, for example construction equipment or, conversely, a small remote control of a vehicle.

\subsection{Defence against VBIED possibilities}

Defence against VBIED can be conducted in many phases. From the momentum when the enemy selects a suitable target for attack, through the preparation and technical implementation of an explosive device in a vehicle, acquisition and often necessary training drivers to real use. It is a system that can be disrupted in any phases. However, if VBIED was already used, the explosion generally has a devastating effect on the target, whether it is a military observation post, the local community at the market or a military base. The key feature of VBIED is surprise factor and mass effect. The basic question is how to actually recognize and identify VBIED from for example, only an inexperienced driver or the driver who is stricken with acute health problems. The answer is practically non-existent. The situation is not changed by the fact that vehicles are armoured, so relatively easily distinguishable from other vehicles.

Small arms fire to VBIED does not have an immediate effect of stopping. Also relatively slow preparation of anti-tank weapons for use again VBIED could result in too late VBID destruction. Vehicle speed $40 \mathrm{kmh}-1$ travelled half a minute distance of over 300 meters. During this time a soldier has to spot potential threats, use an escalation of force rules, and maintain effective fire. Even the death of the driver may not have the immediate effect of VBIED elimination. In addition, anti-tank guns shooting at a moving vehicle is very difficult. Moreover, for its considerable weight, is not ready for immediate use, and it is not possible due to flash back from the rear of the launchers used anytime and anywhere. On a relatively slow missile has a significant influence wind and start the vehicle does not constitute an appropriate target for this type of gun.

\section{Mounted weapons system usage}

The intervention of the mounted weapon has generally liquidation effect on VBIED. Intervention by high-calibre weapons destroyed VBIED immediately, for smaller calibre destruction is given by cadence. Mounted weapon system can destroy a VBIED on large distance, regardless of time of day, which likely will cause an explosive charge blast. The problem is fact that they are difficult to use in urban areas. The urban area could significantly restrict the scope of weapons and detection systems. In the same time there are hi probabilities of collateral damage. Due to a number of objectives that can be effectively struck by VBIED, the requirement of continuous protection of objects and the dispatch of troops action represents use of mounted weapons high demands on logistics and qualified personnel. In addition, such a device, statically positioned to protect the buildings, observation point or object of accommodation of troops, is considered as a very attractive target. There are relatively widespread modern anti-tank missiles (eg. PTRS Cornet) among insurgents which represents high threats for such position.

\section{Non-explosive and explosive barriers usage}

The vehicle carrying explosives can be stopped by roadblocks. It could be used, non-explosive, the explosive, different structures, power (size and weight), different time and technical simplicity, complexity and difficulty of installation.

Non-explosives barriers currently play a crucial role in protecting important buildings, permanent and temporary checkpoints and other static objects. They are usually very robust and capable of withstanding the most massive VBIED explosion. Their massive expansion is hampered by their weight and installation costs. Especially temporary habitats are protected by these objects to a much lesser extent because of the demands on materials, time, labour and special handling 
equipment.

Use of explosive barriers is usually significantly restricted due to contractual obligations to the host countries.

\section{Appropriate roadblock requirement}

When analysing VBIED from multiple databases, hundreds of videos and photos, it was found that up to $90 \%$ is represented by small cars or light truck. They are driven by suicide bombers, or a person who has been forced for this purpose. Insurgents know very well the local conditions and the vehicle can be used very selectively. This type of VBIED could be used not only against soft targets, but also to break through weak spot in any protective measures. Success is then usually developed by offensive infantry action that followed the VBIED explosion.

In general it can be concluded that VBIED intended to destroy outposts, checkpoints, settlements of local administration, etc. should be stopped by light anti-traffic barrier. Against these targets enemy usually do not use powerful VBIED. To be functional, this barrier must not only stop the vehicle, but also to meet the demands for rapid assembly and manipulation in the desired location. Furthermore, there are requirements for an easy way to transport in sufficient quantity (eg. in ISO container). The material used for barrier must be maximally resistant and cannot create additional fragments. Additionally roadblock must be able to stop the vehicle on any terrain without demanding anchoring to the substrate. Also, the price and the technology used must not be too high, because it would reduce its widespread use.

The advantage of such a roadblock must be the fact that if properly used vehicle with explosives stopped at a sufficient distance from potential targets. Regardless of whether it is a VBIED or any other vehicle that needs to be just slid out of the way - is stopped immediately and without immediate reaction unit designed to protect the building. Analysis of a vehicle in connection with recognition of the hostile VBIED is thus affected only subsequently after a stoppage. Subsequently the VBIED is deprived of their main advantages, surprise and rapid movement towards the target. Of course it will not be a complete destruction, but its potential combat effectiveness is greatly reduced and the threat to the building is minimized to an acceptable level.

\section{Conclusion}

VBIED is one of the dominant threats, not only for peacekeeping but also for the local population in contemporary destinations and can be expected in future operations. It presents a risk to military and soft targets that can destroy very effectively. Despite the technological superiority of the coalition armies they are not capable diminish risk without significant economic cost. Protection against this weapon (tactics) is adequately resolved only with objects of special importance. Implementation light flameproof barrier could realistically bring about a significant reduction effect of VBIED and significantly reduce the risks associated with this weapon.

[1] https://intelcenter.com/\#gs.goqK4bk

\section{References}

[2] Open sources 